\title{
O Programa Nacional de Alimentação Escolar em município do estado da Paraíba: um estudo sob o olhar dos beneficiários do Programa'
}

\author{
National School Feeding Program in a municipality \\ of Paraíba state: a study under the viewpoint \\ of those who benefit from the Program
}

Vanessa Messias MUNIZ2

Alice Teles de CARVALHO²

RE S U M O

\section{Objetivo}

Analisar a adesão e a aceitação da alimentação escolar e seus determinantes sob o ponto de vista dos beneficiários do Programa Nacional de Alimentação Escolar.

\section{Métodos}

A amostra foi aleatoriamente composta por 240 alunos da quarta série de 10 escolas municipais de João Pessoa, Paraíba. A análise das perguntas fechadas do questionário foi realizada utilizando-se freqüência simples e teste qui-quadrado. As questões abertas foram categorizadas a partir do conceito central contido nas respostas.

\section{Resultados}

A maioria (87,0\%) dos escolares considerou a alimentação escolar importante e mais de $90 \%$ referiram aderir ao Programa. Desses, 137 (57,3\%) consomem a merenda, às vezes, devido, principalmente, à inadequação de algumas preparações ao hábito alimentar. Quanto à aceitação, 196 escolares afirmaram gostar da alimentação, principalmente por ser saborosa. Também foram positivamente referidas as características de: quantidade $(79,8 \%)$, variedade $(92,9 \%)$, temperatura $(85,8 \%)$, tempo disponível para se alimentar $(63,0 \%)$ e a forma de distribuição $(66,5 \%)$ da alimentação. Os baixos percentuais de escolares que referiram só freqüentar a escola pela oferta da merenda (0,9\%) e deixar de freqüentá-la, caso o Programa de Alimentação Escolar fosse extinto, $(4,4 \%)$ merecem destaque.

\footnotetext{
1 Artigo elaborado a partir da dissertação de V.M. MUNIZ, intitulada "Análise dos fatores envolvidos na aceitabilidade do Programa de Alimentação Escolar no município de João Pessoa, PB, um estudo piloto". Centro de Ciências da Saúde, Universidade Federal da Paraíba; 2006. Apoio financeiro do CNPq (processo: 133146/2005-7).

2 Universidade Federal da Paraíba, Centro de Ciências da Saúde, Departamento de Nutrição. Campus Universitário, s/n., CCS, $2^{\circ}$ andar, Castelo Branco III, 58059-900, João Pessoa, PB, Brasil. Correspondência para/Correspondence to: A.T. CARVALHO. E-mail:<alicetel@terra.com.br>.
} 


\section{Conclusão}

A inadequação ao hábito alimentar e o sabor foram os principais motivos referidos pelas crianças para não aderir e aceitar a alimentação, respectivamente. A adequação do cardápio aos hábitos alimentares e a essencialidade do Programa para reduzir a evasão escolar são fatores que requerem maior investigação.

Termos de Indexação: alimentação escolar; avaliação PNAE; avaliação de programas sociais, estudantes.

\section{A B S T R A C T}

\section{Objective}

To analyze the adherence and acceptance of school food and its determinants under the viewpoint of those who benefit from the program.

\section{Methods}

The sample consisted of 240 fourth-grade students, randomly selected from 10 public schools in the municipality of João Pessoa, Paraíba. Analysis of the closed questions of the questionnaire was done using simple frequency and the chi-square test. The open questions were categorized based on the central concept of the answers.

\section{Results}

Most (87.0\%) of the school children considered the Program important and more than $90.0 \%$ adhered to it. One hundred and thirty seven (57.3\%) of them adhere sometimes, since the food is not always what they are used to eating. Regarding acceptance, 196 school children reported liking the food, mainly because it is tasty. Other characteristics with positive feedback were: quantity (79.8\%), variety (92.9\%), temperature (85.8\%), time available to eat (63.0\%) and the way the food was distributed (66.5\%). The low percentages of school children who reported only going to school for the food (0.9\%) and would drop out of school if the School Feeding Program were canceled (4.4\%) are worth mentioning.

\section{Conclusion}

The main reasons reported by the children for not adhering to the program were lack of familiarity with the food and taste. Adjusting the menu to the children's eating habits and the importance of the program to diminish school evasion are factors that require further investigation.

Indexing terms: school feeding; PNAE assessment; social program assessment; students.

\section{N T R O D U Ç Ã O}

O Programa Nacional de Alimentação Escolar (PNAE) é uma política governamental, de âmbito nacional, que visa a suprir, no mínimo, $15 \%$ das necessidades nutricionais dos escolares durante a permanência na escola. O PNAE objetiva, ainda, contribuir para a redução dos índices de evasão escolar, para a formação de bons hábitos alimentares e para o aumento da capacidade de aprendizagem ${ }^{1,2}$.

Esse Programa atendeu, em 2005, cerca de 37 milhões de alunos matriculados na educação infantil (creches e pré-escolas) e no ensino funda- mental ( $1^{\mathrm{a}}$ a $8^{\mathrm{a}}$ série) da rede pública e das escolas mantidas por entidades filantrópicas cadastradas no Censo Escolar e registradas no Conselho Nacional de Assistência Social ${ }^{1,2}$.

Desde 1994, o PNAE funciona de forma descentralizada, segundo os princípios da Lei 8.913/94, a qual estabelece as diretrizes desse processo. A perspectiva foi de permitir uma maior regularização no fornecimento das refeições, possibilitar melhoria na sua qualidade, atender aos hábitos alimentares dos estudantes, incentivar a economia local e regional, diminuir custos operacionais e estimular a participação da comunidade ${ }^{1,3-5}$. 
Em 1999, a forma de gestão escolarizada passou a integrar o conjunto de possibilidades para o gerenciamento do Programa. Nesse tipo de modalidade, a Prefeitura ou a Secretaria Estadual de Educação operam como convenientes, junto ao Ministério da Educação e Cultura (MEC) e ao Fundo Nacional de Desenvolvimento da Educação (FNDE), recebendo os recursos federais e os transferindo diretamente às unidades escolares, que assumem todas as operações do Programa, o que possibilita maior adaptação dos cardápios aos hábitos alimentares dos alunos e incentivo ao desenvolvimento da economia de cada bairro ${ }^{1,2,6}$.

Os recursos do Programa de Alimentação Escolar são destinados, exclusivamente, à compra de alimentos, devendo 70\% desses serem utilizados na aquisição de produtos básicos. Estes devem estar presentes diariamente no cardápio, elaborado e programado por nutricionista habilitado, com a participação do Conselho de Alimentação Escolar (CAE), devendo o índice de aceitabilidade dos cardápios, por parte dos alunos, ser superior a $85 \%^{2}$.

O modelo escolarizado de gerenciamento é adotado desde 1999 pelo município de João Pessoa, proporcionando uma maior autonomia das escolas para definir, comprar e administrar a confecção dos cardápios. Atualmente, o sistema de escolarização é adotado em toda a rede de ensino e o órgão gestor do Programa é a Secretaria de Educação do Município (SEDEC).

Uma vez que a forma escolarizada apresenta-se como estratégia para uma maior adequação dos programas municipais de alimentação escolar às metas do PNAE, e reconhecendo que a avaliação do cumprimento dessas metas deve contemplar todos os atores envolvidos na gestão e na operacionalização do Programa, incluindo os seus beneficiários, uma equipe de pesquisadores do Departamento de Nutrição da Universidade Federal da Paraíba (UFPB) vem desenvolvendo uma pesquisa intitulada Programa Nacional de Alimentação Escolar (PNAE) no Município de João Pessoa: avaliação do funcionamento e proposta de intervenção, na qual estão inseridos os resultados aqui apresentados.
Frente à premissa segundo a qual a aceitação da alimentação pelos beneficiários está relacionada com a qualidade dos serviços de alimentação prestados pela escola, são apresentados, neste artigo, os resultados do estudo referentes à análise com os escolares. O objetivo é analisar questões relativas à adesão e à aceitação da alimentação escolar e seus determinantes, a partir de uma abordagem quanti-qualitativa dos usuários do PNAE.

\section{MÉ TO D OS}

O estudo foi desenvolvido no município de João Pessoa, tendo sido submetido e aprovado pelo Comitê de Ética em Pesquisa (protocolo 202/05) do Centro de Ciências da Saúde da Universidade Federal da Paraíba.

Em análise prévia do número de escolas em funcionamento no município e sua distribuição nos bairros foram identificadas 89 escolas da rede pública municipal, distribuídas em 41 bairros e que atendem a 5.129 alunos matriculados na quarta série do ensino fundamental.

Para a seleção da amostra, decidiu-se trabalhar com um mínimo de 10\% das escolas municipais atendidas pelo Programa. Inicialmente foram sorteados, aleatoriamente, 10 bairros e, em seguida, sorteou-se uma escola, também aleatoriamente, por bairro.

Para a análise das questões relativas à adesão e à aceitação da alimentação escolar por parte dos estudantes, foram aplicados questionários semi-abertos com 240 alunos matriculados na quarta série do ensino fundamental, do turno diurno, das 10 escolas selecionadas. Considerando que, no ano de 2005, estavam matriculados, na quarta série das escolas em estudo, 341 alunos, a amostra foi composta por 70,4\% desses. A opção por trabalhar com os escolares da quarta série partiu do pressuposto de que, nessa fase escolar, as crianças já se encontram aptas a expressar suas opiniões com clareza e liberdade. 
O instrumento foi estruturado para obter informações sobre a alimentação escolar, com destaque para questões referentes à importância, à adesão, à quantidade, à variedade, a alimentos de maior e menor aceitação e à procedência dos alimentos consumidos na escola (casa, cantina ou fiteiros $^{(3)}$. O índice de adesão correspondeu à medida percentual de alunos que referiram consumir a alimentação preparada pela escola e o índice de aceitação correspondeu à medida percentual de alunos que referiram gostar da alimentação oferecida.

Para a elaboração do questionário foram formuladas 15 questões fechadas com espaços para justificativas e 5 questões abertas, incluindo a solicitação para a elaboração de uma frase sobre a merenda da escola. As questões foram elaboradas com base na literatura da área de alimentação escolar ${ }^{1-3,6}$ e nos objetivos da pesquisa, utilizando-se de linguagem adaptada à população investigada.

Em um primeiro momento da coleta de dados, as escolas foram contactadas e a direção informada sobre os objetivos da pesquisa e sobre a responsabilidade de sua condução pela Universidade. Realizou-se levantamento preliminar do número de alunos matriculados na quarta série de cada escola, a partir dos Diários de Classe. Os termos de consentimento foram entregues para encaminhamento aos pais, com o fim de obter autorização para a participação de seus filhos na pesquisa.

Os questionários foram respondidos pelos alunos (presentes na escola no dia da pesquisa, e cujos pais haviam assinado o termo de consentimento) em sala de aula, sob a supervisão da professora da turma, orientada a não interferir nas respostas, mas facilitar a livre expressão das crianças, esclarecendo que não se tratava de prova do currículo escolar e que a participação era voluntária. Optou-se pela participação da professora, com o intuito de evitar possíveis inibições dos alunos na presença dos pesquisadores. Tal procedimento foi reforçado pelo fato de a pesquisa ter sido realizada no início de uma nova gestão municipal, o que poderia transmitir à escola a idéia de fiscalização por parte da Secretaria de Educação. No entanto, reconhece-se que qualquer escolha metodológica pode enviesar os resultados e que a presença de um agente externo, seja a professora ou um pesquisador, pode induzir respostas favoráveis ao Programa por parte das crianças.

Após o preenchimento, os questionários foram recolhidos pelas professoras e devolvidos, imediatamente, aos pesquisadores.

Para a análise dos dados, foi construído, inicialmente, um banco de dados utilizando-se o software Microsoft Access 2003. A análise das perguntas fechadas do questionário foi realizada com o uso de freqüência simples acompanhada de teste qui-quadrado, utilizando o pacote estatístico Statistical Package for Social Sciences (SPSS) versão 11.0. As justificativas das questões fechadas foram categorizadas, sempre conjuntamente, pelos dois pesquisadores responsáveis, a partir do conceito central contido na resposta e baseadas nos objetivos da pesquisa e na literatura da área de alimentação escolar utilizada como referencial para este estudo. A análise das perguntas abertas foi realizada utilizando-se freqüência simples.

Para a análise das questões fechadas, foi considerada a freqüência de respostas dos alunos que responderam tais questões. Nas justificativas dessas questões, foram consideradas as respostas dos alunos que responderam e justificaram a alternativa marcada.

No tocante aos questionamentos abertos, referentes às citações de alimentos e ao local onde são realizadas as refeições, foi permitido aos alunos fazerem referência a mais de um alimento e local. Dessa forma, os resultados dessas questões foram baseados na freqüência com que cada alimento ou local foi citado.

\footnotetext{
3 Termo utilizado na Região Nordeste, que significa quiosques de comércio popular que vendem guloseimas, sorvetes, salgados etc. freqüentemente vistos nas portas das escolas.
} 


\section{RESULTADOS}

Dos 240 escolares da quarta série que responderam ao questionário, 113 (47,1\%) eram do sexo masculino, com idades entre 9 e 14 anos e 127 (52,9\%) eram do sexo feminino, na faixa entre 9 e 15 anos. A média das idades das crianças de ambos os sexos foi de 10 anos.

A freqüência de respostas às questões fechadas (relacionadas a: importância, adesão, aceitação, procedência dos alimentos consumidos na escola, quantidade, variedade e temperatura dos alimentos ofertados) foi alta (acima de 99,0\%). Em relação às justificativas, observou-se, também, percentual satisfatório, com mais de $86,0 \%$ de explicação das alternativas marcadas. As questões abertas (relacionadas à citação das preparações preferidas, ao local de realização da refeição e à opinião quanto aos alimentos que gostariam que fossem oferecidos pela escola) e a frase (Faça uma frase sobre a merenda da sua escola) sobre a alimentação escolar, tiveram baixo percentual de respostas em branco $(\leq 7,9 \%)$.

A maioria dos alunos considerou a alimentação escolar importante, sendo que apenas dois deles referiram só freqüentar a escola por causa da merenda. Em relação à adesão, os resultados também foram positivos, já que a maioria disse consumir a alimentação escolar, apesar de mais da metade ter relatado consumo esporádico. Essa adesão parece estar acompanhada por uma alta aceitação, visto que prevaleceu o percentual de alunos que referiu gostar da alimentação oferecida pela escola (Tabela 1).

Quanto à importância da alimentação escolar, observa-se, na Tabela 1, que apenas uma minoria dos alunos questionados tem na alimentação o principal motivo para freqüentar a escola. Essa questão é reafirmada ao considerar outra pergunta abordando as conseqüências do não oferecimento da alimentação escolar. Apesar de $37,8 \%(n=90)$ responderem que a supressão da merenda seria negativa, e atribuírem essa dificuldade, sobretudo, à necessidade financeira dos seus pais, apenas $4,4 \%$ referiram que deixariam de vir para a escola, caso o Programa fosse extinto.
Para cada uma das alternativas de respostas da Tabela 1, foram obtidas justificativas e os maiores percentuais de respostas são apresentados nas Figuras 1, 2 e 3.

Tabela 1. Distribuição das respostas dos alunos quanto à importância, à adesão e à aceitação da alimentação oferecida pelas escolas públicas municipais. João Pessoa, PB. 2005

\begin{tabular}{lcr}
\hline Perguntas e respostas & $\mathrm{n}$ & $\%$ \\
\hline Importância & & \\
(Para você, a merenda escolar é importante? Justifique) & \\
Sim & 208 & 87,0 \\
Não & 29 & 12,1 \\
Sim, só venho para a escola porque tem merenda & 2 & 0,9 \\
\hline Total* & 239 & 100,0 \\
\hline Adesão & & \\
(Você come a comida oferecida na escola? Justifique) & \\
Sim, sempre & 80 & 33,5 \\
Sim, às vezes & 137 & 57,3 \\
Nunca & 22 & 9,2 \\
\hline Total* & 239 & 100,0 \\
\hline Aceitação & & \\
(Você gosta da comida oferecida na sua escola? Justifique) & 196 & 82,0 \\
Sim & 30 & 12,6 \\
Não & 13 & 5,4 \\
\hline Não, mas como & 239 & 100,0 \\
\hline Total* & &
\end{tabular}

* As diferenças foram estatisticamente significantes: $p<0,001$.

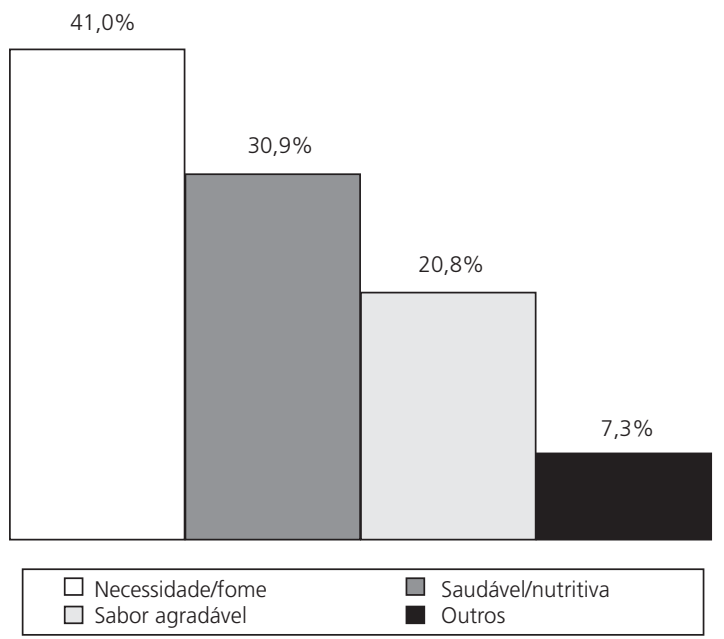

Figura 1. Opinião dos alunos quanto aos motivos da importância da alimentação oferecida pelas escolas públicas municipais. João Pessoa, PB. 2005. 
Na Figura 1, percebe-se que dos 208 alunos que consideraram a alimentação escolar importante, 178 apresentaram justificativa, tendo $41,0 \%(n=73)$ feito menção à dificuldade financeira das famílias ou ao fato de sentir fome na escola. Para 30,9\% ( $n=55)$ a alimentação escolar é importante por ser saudável e nutritiva, e para $20,8 \%(n=37)$, por ser saborosa.

Em relação à adesão, ao considerar a freqüência dos alunos que comem esporadicamente a alimentação escolar ( $n=137)$, observa-se, na Figura 2, que das 123 justificativas, 41,5\% $(n=51)$ dos escolares alegou, como principal motivo, questões relacionadas à inadequação das preparações aos seus hábitos alimentares. Justificativas como eu não gosto de tudo, eu não gosto de sopa e eu não como algumas comidas, foram freqüentes e apontam para o fato de que, independentemente do sabor e da qualidade das refeições ofertadas, tratam-se de preparações que não coincidem com as preferências alimentares dos alunos. Tais respostas geraram uma categoria, denominada pelos autores, de "Inadequação do Cardápio Oferecido (I.C.O)".

Em seguida, tem-se 32,5\% $(n=40)$ dos escolares afirmando não consumir a alimentação escolar quando estavam sem apetite, quando levavam alimentos de casa ou quando compravam nas escolas. Já 14,6\% $(n=18)$ dos alunos referiram não consumir a alimentação nos dias em que

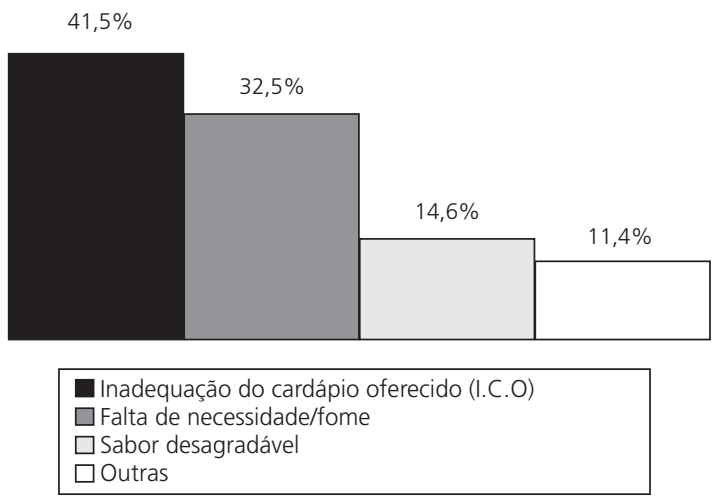

Figura 2. Opinião dos alunos quanto aos motivos da não adesão permanente à alimentação oferecida pelas escolas públicas municipais. João Pessoa, PB. 2005. achavam que a preparação não estava saborosa (Figura 2).

No que se refere à aceitação da alimentação escolar, dos 196 alunos que afirmaram gostar da alimentação, 180 justificaram sua resposta. Verifica-se que a grande maioria $(76,7 \%, n=138)$ alegou gostar, em virtude de a alimentação oferecida ser saborosa. Para 13,3\% ( $n=24)$, a afirmativa de que a alimentação escolar é saudável e nutritiva foi a justificativa dada (Figura 3).

Outra questão importante no processo avaliativo das ações desenvolvidas no Programa de Alimentação Escolar é o seu papel de contribuir para a promoção de hábitos alimentares saudáveis. Nesse sentido, os tipos de alimentos consumidos pelas crianças na escola, sejam esses oferecidos pelo Programa ou de outra procedência, devem ser monitorados.

Neste estudo, dos 239 alunos que responderam ao questionamento sobre o consumo de outros tipos de alimentos além do oferecido na alimentação escolar, mais da metade (50,2\%, $\mathrm{n}=120$ ) relatou também ingerir alimentos trazidos de casa e 17,2\% ( $n=41)$ alimentos comprados na escola. A partir desses dados, percebe-se que mais de $65,0 \%$ das crianças não consomem apenas a alimentação escolar durante a permanência na escola.

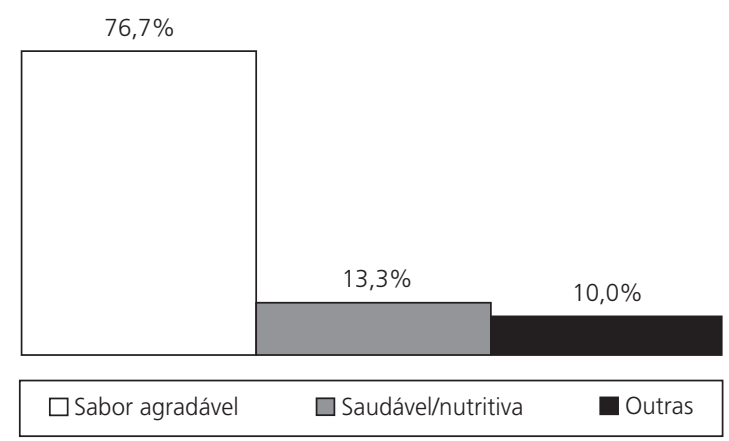

Figura 3. Opinião dos alunos quanto aos motivos da aceitação da alimentação oferecida pelas escolas públicas municipais. João Pessoa, PB. 2005. 
Entre os alimentos mais citados pelos 120 alunos que referiram levar lanches de casa, a bolacha esteve presente em 75,2\% ( $n=90)$ das respostas, seguida pela pipoca, $(22,1 \%, \mathrm{n}=27)$. Quanto aos alimentos comprados na escola, a pipoca foi mencionada por 30 (73,2\%) alunos, seguida pelos salgados, principalmente, coxinha e pastel, citados por 14 escolares, e pela bolacha, que constou em 11 respostas.

Os alunos foram, também, questionados sobre suas preferências em relação à alimentação oferecida na escola, tendo 237 respondido a essa questão. Entre os diversos alimentos referidos como aqueles de que eles mais gostavam, o biscoito esteve presente em 40,5\% ( $n=96)$ das respostas, seguido pelo iogurte $(30,0 \%, n=71)$ e pelo suco $(24,5 \%, n=58)$.

Das preparações de que as crianças referiram não gostar, as sopas foram mencionadas por $31,7 \%(n=75)$, a macarronada, por $19,4 \%$ $(n=46)$ e o mungunzá por $12,2 \% \quad(n=29)$ das respostas.

Ainda no tocante às preferências alimentares, ao serem perguntados sobre os alimentos que gostariam que fossem servidos pela escola, dos 206 alunos que responderam a essa questão, 24,3\% ( $n=50)$ incluíram o cachorro quente (embora essa preparação conste nos cardápios das escolas). A bolacha e as frutas também estiveram presentes em $22,8 \%(n=47)$ e $14,6 \%$ $(n=30)$ das respostas. O refrigerante $(13,6 \%, n=28)$ e o bolo recheado $(12,1 \%, n=25)$ apareceram, porém, em percentuais menores.

Algumas afirmativas de alunos demonstram que esses tendem a limitar a alimentação escolar a uma "merenda" e não a uma refeição. As frases descritas a seguir refletem esta idéia: "só não como a merenda quando é comida de panela, porque eu acho que essas comidas não devem ser oferecidas em um lanche"; "só não como a merenda quando é sopa porque ela é um jantar e não um lanche"; "A merenda da minha escola devia ter mais coisas como biscoito, pipos(4), chocolate" e "Eu queria que na merenda da minha escola fosse servido pipos, hambúrguer, pizza, coxinha, cachorro quente, churrasco, lanches".

Em relação à participação dos escolares na seleção das preparações oferecidas na escola, a partir do questionamento: você ajuda a escolher o que vai ser servido na merenda da sua escola? evidenciou-se que, entre os 238 escolares que responderam, a grande maioria $(96,6 \%, \mathrm{n}=230)$ referiu nunca ter opinado.

No tocante às características organolépticas das merendas, na Tabela 2, são mostrados os dados referentes à quantidade, à variedade e à temperatura dos alimentos. Em relação à quantidade, observa-se que de 238 alunos, 79,8\% ( $n=190)$ relataram ficar satisfeitos com a porção servida. Esse resultado pode ser atribuído ao fato de que, em todas as escolas envolvidas no estudo, é permitido aos alunos repetirem as preparações, se o desejarem. A maioria, de 239 escolares, também considerou a alimentação variada $(92,9 \%, \mathrm{n}=222)$ e a temperatura das preparações servidas adequada ao paladar $(85,8 \%, \mathrm{n}=205)$.

A forma de distribuição da alimentação, o tempo disponível e o local para se alimentarem também foram questionados e referidos positivamente pelos escolares, tendo a maioria deles $(66,5 \%, n=159)$ relatado que a organização dos alunos para receber a merenda se dá em filas rápidas e o tempo disponível para se alimentar e brincar é suficiente $(63,0 \%, n=150)$. Quanto ao local utilizado para se alimentarem, 232 alunos responderam, tendo o refeitório sido mencionado por 33,6\% $(n=78)$. A sala de aula esteve presente em $28,9 \%(n=67)$ das respostas, seguida pelo pátio $(27,2 \%, n=63)$.

Outro aspecto importante está relacionado à falta da alimentação escolar. Observou-se que, diante da pergunta: "falta comida na sua escola?" dos 240 escolares, a maioria $(64,2 \%, n=154)$, declarou nunca ter faltado. Um percentual de $34,2 \%$ ( $n=82$ ) de alunos, no entanto, referiu que a merenda não foi servida algumas vezes.

\footnotetext{
$\overline{4}$ Termo utilizado para designar salgadinhos industrializados destinados ao consumo, principalmente, infantil.
} 
Tabela 2. Distribuiçã̃o das respostas dos alunos quanto à quantidade, à variedade e à temperatura da alimentação oferecida pelas escolas públicas municipais. João Pessoa, PB. 2005.

\begin{tabular}{lrr}
\hline Perguntas e respostas & $\mathrm{n}$ & $\%$ \\
\hline Quantidade & & \\
(A quantidade de comida servida a você na escola é:) & \\
Boa, fico satisfeito & 190 & 79,8 \\
Exagerada & 10 & 4,2 \\
Pouca, ainda fico com fome & 38 & 16,0 \\
\hline Total* & 238 & 100,0 \\
\hline Variedade & & \\
(A comida oferecida na escola é variada?) & 222 & 92,9 \\
Sim, sempre tem comidas diferentes & 17 & 7,1 \\
Não, quase todo dia é a mesma preparação & 239 & 100,0 \\
\hline Total* & & \\
\hline Temperatura & & \\
(A temperatura da comida servida na escola é:) & 205 & 85,8 \\
Boa & 17 & 7,1 \\
Quente & 17 & 7,1 \\
\hline Fria & 239 & 100,0 \\
\hline Total* & &
\end{tabular}

* As diferenças foram estatisticamente significantes: $p<0,001$.

\section{I S C U S S Ã O}

Os resultados deste estudo mostraram que as crianças consideram a alimentação escolar importante, mas não uma condição para a sua permanência na escola. E ainda, a maioria dos escolares referiu consumir outros alimentos além daqueles oferecidos pela escola.

Estes dados tornam-se particularmente relevantes e requerem maiores investigações, considerando que no Brasil o PNAE tem sido apontado como um Programa assistencialista para muitas crianças que têm na alimentação escolar a sua principal refeição, e que um dos principais objetivos deste Programa é contribuir para a redução da evasão escolar ${ }^{7,8}$.

Por outro lado, essa questão ganha uma conotação ainda mais relevante ao considerar que o ambiente escolar não pode ser tomado como solução para o problema da fome, sob pena de comprometer a função pedagógica. De acordo com Ceccim", se a alimentação escolar se sobrepuser à ação pedagógica de ensinar, estará substi- tuindo a deficiência alimentar pela deficiência educacional, reforçando, assim, a exclusão social.

A interpretação dessa questão, no entanto, requer cautela, tendo em vista a faixa etária dos escolares inseridos neste estudo. Nesse sentido, vale mencionar, a partir de entrevista com os pais $(n=237)$ desses alunos, que, para 97,9\% $(n=232)$ deles, a alimentação escolar foi considerada importante, tendo $23,3 \%(n=54)$ acrescentado que o Programa é também fundamental para a permanência de seu filho na escola.

Os altos índices de adesão e aceitação da alimentação pelos beneficiários, observados neste estudo, corroboram os relatos da literatura ${ }^{6,7,10,11}$.

O PNAE preconiza a realização de testes de aceitabilidade antes da introdução de um novo alimento ou preparação, e sempre que se fizer necessário, com metodologia definida pela entidade executora, considerando um índice de aceitação não inferior a $85 \%{ }^{7}$.

Em uma pesquisa realizada pelo $\mathrm{FNDE}^{10}$, em 2001, a adesão diária dos alunos à alimentação escolar foi referida satisfatoriamente por $76,1 \%$ dos pesquisados.

Na presente pesquisa, apesar de a grande maioria ter referido aderir à alimentação escolar, prevaleceram aqueles que mencionaram adesão esporádica. Evidenciou-se que aspectos relacionados à fome, aos hábitos alimentares e ao sabor das preparações interferem na adesão e na aceitação da alimentação escolar pelas crianças.

Estas conclusões são concordantes com as obtidas no estudo de Martins et al. ${ }^{11}$ sobre a aceitabilidade da alimentação oferecida em escolas estaduais e municipais de Piracicaba, SP, o qual constatou que 372 alunos pesquisados aderem à alimentação escolar, principalmente, por gostarem da alimentação (67\%) e por sentirem fome (18\%). Os 108 escolares que referiram não aderir apresentaram como justificativas não gostar da alimentação servida (48\%), trazer lanche de casa $(16 \%)$ ou não sentir fome na escola.

Em pesquisa desenvolvida por Flávio et al. ${ }^{6}$, que também objetivou avaliar a aceitação e a 
adesão à alimentação escolar, 72\% dos alunos tinham o hábito de consumir a alimentação oferecida pela escola. No que se refere à aceitação da alimentação, os resultados do mesmo estudo também se mostraram positivos, com $76 \%$ dos escolares referindo que o serviço de alimentação escolar estava entre bom e ótimo.

Em relação ao consumo alimentar nas escolas, no presente estudo, observou-se que a maioria das crianças consome outros tipos de alimentos além da alimentação escolar, seja trazendo lanches de casa ou comprando alimentos na própria escola.

É importante referir o papel do PNAE como estratégia de educação nutricional para aquisição de bons hábitos alimentares. Ou seja, caso as crianças não adquiram hábitos alimentares saudáveis, estimuladas por preparações nutritivas, saborosas e atrativas para a faixa etária escolar, as refeições oferecidas, dificilmente, serão bem aceitas. Uma maior participação do escolar no processo de seleção e preparo da alimentação oferecida na escola pode contribuir para tanto, o que não foi constatado neste estudo. Vários estudos ${ }^{6,7-16}$ têm relatado a prática de consumo de outros alimentos por parte dos escolares durante a permanência na escola.

No trabalho de Sturion et al. ${ }^{12}$, a maioria (70\%) dos escolares que afirmou não participar do Programa freqüentava unidades de ensino que apresentavam cantinas escolares.

Os resultados identificados no trabalho de Flávio et al. ${ }^{6}$ contrastam com os apresentados neste estudo, considerando que, ao buscar conhecer os tipos de alimentos consumidos pelas crianças durante a permanência na escola, esses autores verificaram que a maioria (68\%) relatou consumir apenas a alimentação escolar, pela inexistência de cantinas ou lanchonetes nas escolas.

Essa prática de consumo de alimentos oriundos de casa ou de cantinas revela-se, portanto, preocupante para o alcance das metas do $P N A E$, que, mais do que um Programa de suplementação alimentar, deve ser visto como um importante instrumento de educação nutricional e um canal para resgatar hábitos alimentares saudáveis ${ }^{7}$.

A alta ingestão de alimentos industrializados e de valor nutricional reduzido, provenientes de casa ou das cantinas escolares, também merece destaque, ao considerar que tal consumo tem sido relacionado à obesidade, não somente quanto ao volume de alimentos, mas também à composição e à qualidade da dieta. A mudança dos padrões alimentares, caracterizados pelo pouco consumo de frutas e hortaliças e pelo aumento no consumo de guloseimas (bolachas recheadas, salgadinhos, pipocas e doces), está relacionada com o aumento da adiposidade em crianças $^{13}$.

Para Gross \& Cinelli ${ }^{14}$, um dos fatores que prejudica o consumo da alimentação escolar é a permissão da venda de alimentos "competitivos", com valor nutricional mínimo, ricos em sódio e gordura saturada, vendidos em lanchonetes na própria escola ou em locais próximos. A facilidade de acesso por parte dos escolares a esses tipos de alimentos contribui para uma menor aceitação e adesão à alimentação escolar, podendo provocar desvios nutricionais que interferem no crescimento e no desenvolvimento.

De acordo com documento da II Conferência Nacional de Segurança Alimentar e Nutricional, realizada em 2004, a cantina, como parte do ambiente escolar poderia ser vista como um espaço educativo importante para estimular o consumo de determinados alimentos, influenciando escolhas saudáveis em função do que está exposto à venda ${ }^{15}$.

Boog $^{16}$, em seu estudo sobre a contribuição da educação nutricional para a construção da segurança alimentar, ressalta que os alimentos consumidos na escola, sejam procedentes da alimentação escolar, de lanches trazidos de casa ou comprados em cantinas, devem ser, igualmente, saudáveis.

Além da necessidade de manter o equilíbrio entre os alimentos consumidos na escola, coibindo a venda de produtos com alta concen- 
tração energética e elevado teor de sódio e corantes artificiais, deve-se considerar que as preferências alimentares infantis sofrem forte influência do marketing de produtos alimentícios, o que requer atenção no planejamento dos cardápios da alimentação escolar, bem como no processo de regulamentação das cantinas e no controle dos alimentos provenientes de casa ${ }^{15}$.

A aceitação da alimentação pelas crianças é um dos principais fatores que determinam a qualidade dos serviços de alimentação das escolas. Portanto, pesquisas de preferências alimentares são fundamentais para averiguar essa aceitação.

Na presente pesquisa, alimentos como biscoitos e iogurte foram citados como os de predileção entre os escolares. O oposto foi observado para preparações compostas por sopas e macarronadas. Em estudos semelhantes, a maioria dos escolares mencionou preferir preparações, como macarronada e arroz, embora a sopa também tenha constado como um dos alimentos de menor aceitação $0^{6,11}$.

O diálogo com os escolares, portanto, é fundamental para que os alimentos oferecidos não sejam vistos como uma imposição e que o não oferecimento de alguns alimentos que fazem parte do hábito alimentar infantil, mas que não trazem benefícios à saúde, não seja visto pelas crianças como algo proibitivo ${ }^{15}$.

Destaque especial pode ser dado ao desenvolvimento de hortas no espaço escolar. É papel da escola estimular nas crianças o interesse pelo plantio, não só porque a criação de hortas seria uma experiência importante para o desenvolvimento da chamada "agricultura urbana", praticada com êxito em vários países e referida como uma das ações estratégicas do Programa Fome Zero, mas também porque as diferentes atividades envolvidas (preparação do terreno, plantio, cuidados com a planta, colheita e, depois, a preparação dos alimentos) poderiam transformar as hortas em instrumentos pedagógicos, e possibilitariam o aumento no consumo de frutas e hortaliças, o resgate dos hábitos regionais e locais, além da diminuição dos custos com a compra desses produtos $^{15}$.

Em alguns estados brasileiros, essa prática tem atingido resultados positivos, como o obtido em município do interior do Paraná, que economizou $85 \%$ do recurso destinado à compra de frutas e verduras, após implantar hortas nas escolas ${ }^{7}$.

Apesar de que as hortas escolares possam contribuir para a aquisição de bons hábitos alimentares e, ainda, fornecer produtos saudáveis para a preparação da alimentação, observou-se, nas 10 escolas incluídas no estudo, a inexistência de qualquer trabalho nesse sentido.

Outros fatores que também interferem na aceitação, tais como a quantidade, a variedade e a temperatura dos alimentos servidos, foram referidos de forma positiva no presente estudo.

De acordo com Ornelas ${ }^{17}$, as preparações apresentadas em um cardápio devem, primeiramente, estar de acordo com as preferências do público ao qual se destina, além de conter uma harmonia, dada pela combinação correta dos alimentos, cores, sabores, consistência, o que exige sentido estético, buscando, sempre, suprir as necessidades nutricionais dos comensais.

O FNDE preconiza para o PNAE que os cardápios sejam elaborados por nutricionista habilitado, com participação no CAE. Nesse planejamento, a quantidade de alimento per capita oferecido deve ser baseada na faixa etária correspondente, e ser suficiente para suprir, no mínimo, 15\% das recomendações energéticas diárias de cada grupo ${ }^{1}$. Seria recomendável, contudo, que o aporte nutricional das refeições servidas aos escolares fosse baseado em dados da realidade de cada município ou estado, e não em metas nacionais, visto que a carência nutricional difere de uma região para outra. Em paralelo à descentralização administrativa do PNAE, deveria ocorrer, também, a descentralização das normas nutricionais do Programa.

Em relação à variedade e à temperatura das preparações, o clima da região e a época do ano devem ser considerados, para evitar a mono- 
tonia alimentar do cardápio que pode prejudicar a aceitação da alimentação escolar. Receitas variadas, distintas formas de preparação de um mesmo alimento e combinações diferentes entre alimentos são positivas ${ }^{7}$.

Com relação à distribuição da merenda e ao tempo disponível para se alimentar, a formação de filas para a entrega da alimentação permite uma melhor organização no processo de distribuição, otimizando o tempo, possibilitando um maior controle pelas merendeiras no porcionamento e desenvolvendo, nas crianças, senso de respeito e interação com os colegas.

Essa forma de distribuição também foi verificada por $\mathrm{Abreu}^{8}$, ao investigar a prática do Programa em Porto Alegre. De acordo com a autora, em algumas escolas, os alunos recebem o lanche em filas e se alimentam no pátio, já em outras, as crianças consomem a alimentação em refeitórios adequadamente equipados. $\mathrm{Na}$ presente pesquisa, a maioria dos escolares referiu consumir a alimentação no refeitório.

Ainda em relação ao oferecimento dos alimentos, a maioria dos escolares afirmou nunca ter faltado alimentação na escola, o que constitui uma informação importante para a própria credibilidade do Programa no município de João Pessoa.

Relativamente aos recursos financeiros, o FNDE preconiza, que o total de parcelas repassadas às entidades executoras deve cobrir os 200 dias letivos de alimentação escolar, não sendo possível faltar alimentação durante esse período. Uma participação mais efetiva dos escolares, bem como dos seus responsáveis, nas etapas referentes à aplicação dos recursos e aos gêneros alimentícios adquiridos, poderia contribuir para a garantia do oferecimento diário da alimentação escolar. Além disso, cabe a esses atores e aos demais membros da sociedade, levar ao conhecimento do CAE e dos órgãos públicos (FNDE, Ministério Público Federal, Poder Executivo Federal e Tribunal de Contas da União) qualquer irregularidade envolvendo o PNAE, contribuindo, assim, para o exercício da cidadania”.

\section{CONCLUSÃ O}

Com base nos resultados obtidos, conclui-se que os diferentes aspectos relacionados à alimentação escolar abordados neste estudo foram referidos positivamente pela maioria dos escolares envolvidos e que, apesar disso, a oferta dessa alimentação não é condição para que as crianças freqüentem a escola. Percebeu-se, ainda, que, apesar de a alimentação escolar ter sido considerada importante frente às dificuldades financeiras das famílias, ou devido à fome das crianças, durante a permanência na escola, o sabor das preparações, bem como a adequação dos cardápios aos hábitos alimentares dos escolares, parecem exercer forte influência na assiduidade dos mesmos ao Programa de Alimentação Escolar.

O instrumento desenvolvido para a realização deste estudo conseguiu medir os diferentes aspectos que se objetivou estudar, relativos à adesão e à aceitação da alimentação escolar por parte dos beneficiários.

A freqüência de respostas, em todas as questões abertas e fechadas do questionário, foi alta, mostrando que a linguagem utilizada, dotada de termos freqüentemente usados pela clientela em estudo, favoreceu o entendimento.

\section{COLABORADORES}

V. MESSIAS aplicou os questionários e participou do desenvolvimento da metodologia e redação. A.T. CARVALHO idealizou a proposta da pesquisa, participou do desenvolvimento da metodologia e da redação.

\section{REFER Ê N CIAS}

1. Brasil. Ministério da Educação. Fundo Nacional de Desenvolvimento da Educação. Alimentação Escolar [acesso 25 set 2005]. Disponível em: http: //www.fnde.gov.br

2. Weis B, Chaim NA, Belik W. Vamos fiscalizar a merenda escolar: de volta à luta contra a corrupção eleitoral [acesso 25 ago 2004]. Disponível em: http://www.apoiofomezero.org.br/site/upload/ cartilha.pdf 
3. Spinelli MAS, Canesqui AM. O programa de alimentação escolar no estado de Mato Grosso: da centralização à descentralização (1979-1995). Rev Nutr. 2002; 15(1):105-17.

4. Pipitone MAP, Ometto $A M H$, Silva MV, Sturion $G L$, Furtuoso MCO, Oetterer M. Atuação dos conselhos municipais de alimentação escolar na gestão do Programa Nacional de Alimentação Escolar. Rev Nutr. 2003; 16(2):143-54.

5. Vianna RPT, Tereso MJA. O programa de merenda escolar de Campinas: análise do alcance e limitações do abastecimento regional. Rev Nutr. 2000; 13(1):41-9.

6. Flávio EF, Barcelos MFP, Lima AL. Avaliação química e aceitação da merenda escolar de uma escola estadual de Lavras, MG. Ciênc Agrotec. 2004; 28(4):841-7.

7. Weis B, Whitaker W, Chaim NA, Belik W. Manual de gestão eficiente da merenda escolar [acesso 25 ago 2004]. Disponível em: http: //www. fomezero.org.br

8. Abreu M. Alimentação escolar: combate à desnutrição e ao fracasso escolar ou direito da criança e ato pedagógico? In: Em aberto: merenda escolar. Brasil: Ministério da Educação e do Desporto; 1995.

9. Ceccim RB. A merenda escolar na virada do século: agenciamento pedagógico da cidadania. In: Em aberto: merenda escolar. Brasília: Ministério da Educação e do Desporto. 1995.

10. Brasil. Ministério da Educação e do Desporto. Avaliação do impacto distributivo e elaboração de sistemática de monitoramento do PNAE. Brasília; 2005 [acesso 20 dez 2005]. Disponível em: http:// www.fnde.gov.br/apresentacoes/apresentacao $01 / / \mathrm{Html}$

11. Martins RCB, Medeiros MAT, Ragonha GM, Olbi $J H$, Segatti MEP, Osele MR. Aceitabilidade da alimentação escolar no ensino público fundamental. Saúde Rev. 2004; 6(13):9-15.

12. Sturion GL, Silva MV, Ometto AMH, Furtuoso COM, Pipitone MAP. Fatores condicionantes da adesão dos alunos ao Programa de Alimentação Escolar no Brasil. Rev Nutr. 2005; 18(2):167-81.

13. Triches RM, Giugliani ERJ. Obesidade, práticas alimentares e conhecimentos de nutrição em escolares. Rev Saúde Pública. 2005; 39(4):541-7.

14. Gross SM, Cinelli B. Coordinated School Health Program and dietetics professionals: partners in promoting healthful eating. J Am Diet Assoc. 2004; 104(5):793-8.

15. Brasil. Conferência Nacional de Segurança Alimentar. Alimentação e educação nutricional nas escolas e creches. Brasília; 2005 [acesso 20 dez 2005]. Disponível em: http://www.fomezero.gov.br/ conferencia/Arquivos/Pdf/11-Alimentacao_ Educacao.pdf

16. Boog MCF. Contribuições da educação nutricional à construção da segurança alimentar. Saúde Rev. 2004; 6(13):17-23.

17. Ornelas LH. Técnica dietética: seleção e preparo de alimentos. São Paulo: Atheneu; 2001.

Recebido em: 10/4/2006

Versão final reapresentada em: 30/10/2006 Aprovado em: 5/2/2007 